\title{
$\left[{ }^{68} \mathrm{Ga}\right] \mathrm{Ga}-\mathrm{DOTA}$-TATE uptake due to COVID-19 vaccination
}

\author{
Michal Weiler-Sagie ${ }^{1,2}$ (1) Elizabeth E. Half ${ }^{2,3}$
}

Received: 22 March 2021 / Accepted: 11 May 2021 / Published online: 22 May 2021

(C) The Author(s), under exclusive licence to Springer-Verlag GmbH Germany, part of Springer Nature 2021

A 61-year-old female was referred to $\left[{ }^{68} \mathrm{Ga}\right] \mathrm{Ga}$-DOTATATE-PET/CT for suspected neuroendocrine tumor (NET). She suffered from intractable peptic disease, and her chromogranin A had reached a level of $1447 \mathrm{ng} / \mathrm{ml}$. There was a focus of pathological $\left[{ }^{68} \mathrm{Ga}\right] \mathrm{Ga}$-DOTA-TATE uptake in the head of the pancreas, consistent with NET. There was increased uptake in lymphadenopathy in the left axilla and faint uptake in the left upper arm. pathological uptake in the head of the pancreas (dashed circle). Faint uptake in stranding of the subcutaneous fat in the left upper arm is depicted (arrowhead) in an axial slice of fused PET/CT (b), CT (c), PET (d), and MIP (a). Increased uptake in numerous lymph nodes with cortical thickening in the left axilla and retro-pectoral region is depicted (arrow) in an axial slice of fused PET/CT (b), CT (c), PET (d), and MIP (a).
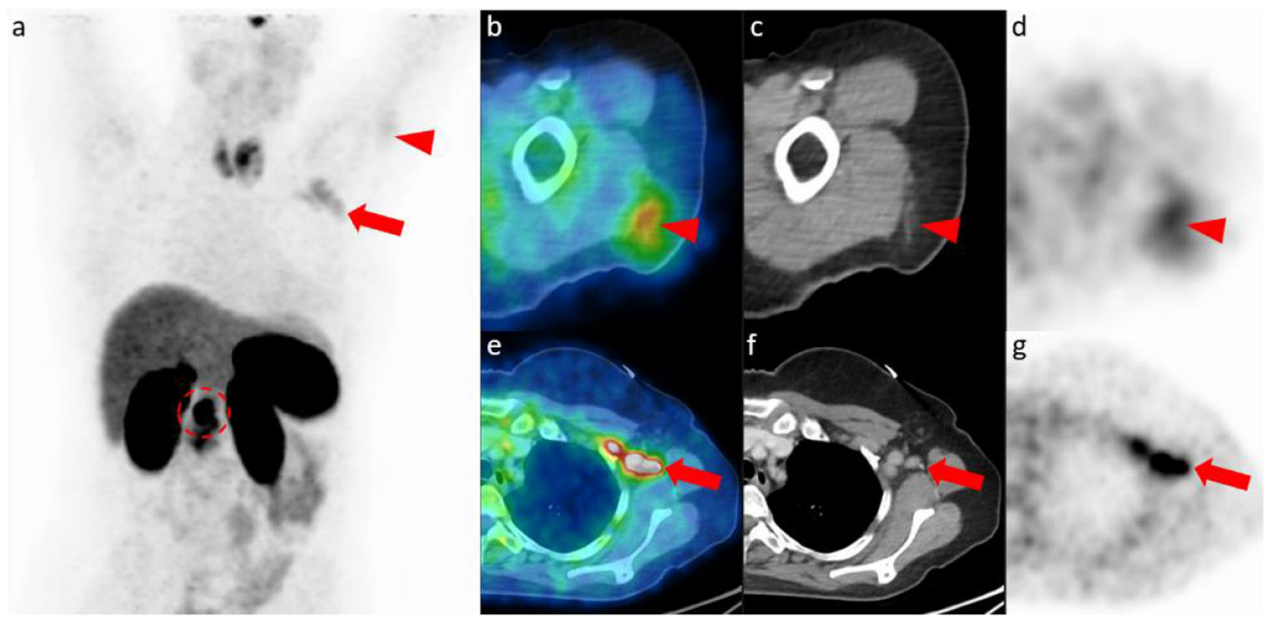

[68]GA-DOTATATE-PET/CT maximal intensity projection (MIP) right anterior oblique view (a) shows focal

This article is part of the Topical Collection on Image of the month

Michal Weiler-Sagie

m_weiler@rmc.gov.il

1 Department of Nuclear Medicine, Rambam Health Care Campus, Haifa, Israel

2 Rappaport Faculty of Medicine, Technion - Israel Institute of Technology, Haifa, Israel

3 Department of Gastroenterology, Rambam Health Care Campus, Haifa, Israel
The patient received the second dose of the PfizerBioNTech COVID-19 vaccine 2 days prior to the PET/CT, as an intra-muscular shot to the left deltoid. The first dose was administered 21 days prior to the second dose.

Lymphatic tissues including lymph nodes are known to express somatostatin receptors [1], and [68]GA-DOTATATE uptake is commonly seen in reactive lymph nodes [2]. This case demonstrates [68]GA-DOTA-TATE uptake due to COVID-19 vaccination in a pattern identical to that of FDG uptake following COVID-19 vaccination $[3,4]$. Nuclear medicine physicians and referring physicians should be aware of this classic pattern. History of recent vaccination localized to the site of uptake should confirm the diagnosis and obliviate the need for further testing. 


\section{References}

1. Reubi JC, Waser B, Horisberger U, Krenning E, Lamberts SWJ, Gebbers J-O, et al. In vitro autoradiographic and in vivo scintigraphic localization of somatostatin receptors in human lymphatic tissue. Blood. 1993;82:2143-51.

2. Kagna O, Pirmisashvili N, Tshori S, Freedman N, Israel O, Krausz Y. Neuroendocrine tumor imaging with 68Ga-DOTA-NOC: physiologic and benign variants. American Journal of Roentgenology American Roentgen Ray Society. 2014;203:1317-23.
3. Eifer M, Eshet Y. Imaging of COVID-19 vaccination at FDG PET/ CT. Radiol Radiol Soc N Am. 2021;210030.

4. Nawwar AA, Searle J, Hagan I, Lyburn ID. COVID-19 vaccination induced axillary nodal uptake on [18F]FDG PET/CT. European Journal of Nuclear Medicine and Molecular Imaging [Internet]. 2021 Feb 26:1-2. ; Available from: https://doi.org/10.1007/s00259021-05274-7.

Publisher's note Springer Nature remains neutral with regard to jurisdictional claims in published maps and institutional affiliations. 